\title{
Biomass allocation in five semi-arid afforestation species is driven mainly by ontogeny rather than resource availability
}

\author{
Florent Noulèkoun $^{1,2} \cdot$ Asia Khamzina $^{3} \cdot$ Jesse B. Naab ${ }^{2} \cdot$ John P. A. Lamers $^{1}$
}

Received: 31 August 2017 / Accepted: 14 November 2017 / Published online: 28 November 2017

(C) INRA and Springer-Verlag France SAS, part of Springer Nature 2017

\begin{abstract}
- Key message The changes in the relative biomass allocation to roots in juvenile stands of fast-growing (Leucaena leucocephala Lam., Moringa oleifera Lam., and Jatropha curcas L.) and slow-growing (Anacardium occidentale L. and Parkia biglobosa Jacq.) afforestation species are driven mainly by ontogeny rather than resource availability. However, silvicultural management aiming at increasing availability of water and particularly nutrients enhances biomass production in all species.

- Context Understanding the patterns of biomass allocation among tree species in response to ontogeny and to variation in resource availability is key to the successful restoration of degraded land using forest plantations.

- Aims This study assessed the effects of resource availability and ontogeny on biomass accumulation and partitioning in five semi-arid afforestation species.

- Methods The aboveground and belowground biomass production of fast-growing Leucaena leucocephala Lam., Moringa oleifera Lam., and Jatropha curcas L. and slow-growing Anacardium occidentale L. and Parkia biglobosa Jacq. was monitored following the application of manure $\left(1 \mathrm{~kg} \mathrm{plant}^{-1}\right)$ and/or supplemental irrigation $(0.5 \mathrm{~L}$ per sapling daily) during the first two rainy seasons and the intervening dry season on degraded cropland in Northern Benin.

- Results Biomass accumulation in the fast-growing species was positively impacted by fertilization and irrigation during both rainy seasons. The slow-growing species responded positively to the silvicultural treatments during the dry and second rainy season. The application of fertilizer alone increased the biomass of P. biglobosa by up to 335\% during the dry season. Fifteen months after planting, manure-treated $L$. leucocephala accumulated the most biomass $\left(2.9 \mathrm{~kg}\right.$ tree $\left.{ }^{-1}\right)$. The root fraction decreased with increasing tree size in all species. The comparison of root versus shoot allocation in trees of equal size indicated that the treatment-induced shifts in biomass partitioning were controlled by ontogeny, which explained 86-95\% of the variation in root-shoot biomass relationships.

- Conclusion While ontogeny was the main driver of biomass partitioning, increased resource availability induced a larger production of biomass, overall leading to greater aboveground production in all species.
\end{abstract}

Handling Editor: Michael Tausz

Contribution of the co-authors All authors conceived and designed the experiment. FN and JBN collected the field data. FN performed statistical analyses and composed the manuscript. AK, JBN, and JPAL contributed to the development of the manuscript.

Electronic supplementary material The online version of this article (https://doi.org/10.1007/s13595-017-0676-4) contains supplementary material, which is available to authorized users.

Asia Khamzina

asia_khamzina@korea.ac.kr

1 Center for Development Research (ZEF), Bonn University, Walter-Flex-Straße 3, 53113 Bonn, Germany

2 West African Science Service Center on Climate Change and Adapted Land Use (WASCAL), P.O. Box 9507, Ouagadougou 06, Burkina Faso

3 Division Environmental Science and Ecological Engineering, Korea University, 145 Anam-Ro, Seongbuk-Gu, Seoul 02841, South Korea
Keywords Intensive silviculture $\cdot$ Manuring $\cdot$ Drip irrigation · Roots · Optimum partitioning theory

\section{Introduction}

Conserving and restoring natural forests is essential in coping with the growing demand for timber and non-timber forest products and ensuring environmental sustainability in tropical regions (Steege et al. 2015). In sub-Saharan Africa (SSA), these efforts are increasingly constrained by the decline in the per capita availability of agricultural land (de Graaff et al. 2011), required to satisfy the food, feed, and fuel demands of the ever-increasing population. The resulting pressure on marginal land (Azuka et al. 2015) has dramatically reduced the duration of fallows, the traditional practice used to restore soil fertility (Nandwa 2001). The increasing variability 
of rainfall in SSA (Sylla et al. 2016) has become an additional obstacle for efforts to improve cropland productivity and regenerate forest areas. In this regard, the afforestation of degraded cropland and intercropping with multi-purpose tree species offer the possibility of increasing on-farm tree cover, reversing land degradation, and contributing to rural livelihoods (Chamshama and Nduwayezu 2002; Garrity et al. 2010; Khamzina et al. 2012).

Though afforestation is a promising strategy, nutrient and water limitations on degraded land may hamper its success. Intensive silviculture, including fertilization, irrigation, pest control, and weed control, has been successful in overcoming environmental constraints and increasing forest production (e.g., Fening and Gershenzon 2002; Mead 2013; Coyle et al. 2016). However, this is yet to be adopted in most dryland afforestation systems due to insufficient incentives for farmers to invest in ecological restoration (e.g., Djalilov et al. 2016) but is practiced for tree species of commercial importance, such as Jatropha curcas L. in biofuel production (Baumert et al. 2016). For instance, fertilization alone mitigated the negative effects of nutrient stress, resulting in enhanced stem growth (6-30\%) in J. curcas and Parkia biglobosa Lam. saplings on nutrient-poor soils under semi-arid conditions (Noulèkoun et al. 2017) and greater aboveground biomass (AGB) accumulation (125-200\%) in two 3-year-old Populus deltoides genotypes in a temperate climate (Coyle and Coleman 2005). Irrigation also improved tree productivity under scarce and erratic rainfall (Khamzina et al. 2008; Trichet et al. 2008; Noulèkoun et al. 2017). Early growth responses of trees to silvicultural treatments are reflected in the adjustment of biomass partitioning between roots and shoots. This relative allocation of biomass can be indicative of the physiological potential and long-term growth trajectory of tree species (e.g., Niklas 1994; Mcconnaughay and Coleman 1999; Reich 2002; Lamers et al. 2006). Critical physiological processes regulating resource acquisition and plant growth under nutrient and/or water stress occur belowground (Coyle and Coleman 2005). Hence, the root share can account for a substantial portion of total biomass (27-68\%) in (sub-)tropical dry forests or plantations (Mokany et al. 2006).

Variations in belowground biomass (BGB) proportions during tree growth are controlled by both resource availability and development (i.e., ontogeny) (Coyle et al. 2008, 2016). Increased resource availability (e.g., nutrient and water) enhances AGB accumulation (which is usually of interest to farmers) as a result of allocation shifts from root to shoot (e.g., Albaugh et al. 1998; Mcconnaughay and Coleman 1999; Coleman et al. 2004; Coyle et al. 2016). Changes in the relative biomass allocation to roots in response to resource availability are predicted to accord with the optimum partitioning theory (OPT), which suggests that plants allocate more biomass to the organ that acquires the most limiting resource (Brouwer 1963; Bloom et al. 1985). However, studies comparing plasticity in root/shoot ratios at common plant size or development stage (not at common plant age or time) have suggested that the shifts in biomass partitioning cited in support of the OPT may largely be induced by accelerated development (e.g., Mcconnaughay and Coleman 1999; Coleman et al. 1994, 2004). Therefore, it is important to separate the dynamics of development-induced (i.e., ontogenetic drift) changes in biomass allocation from those modulated by silvicultural treatments (i.e., "true" plasticity in allocation) when identifying the controlling factors (Mcconnaughay and Coleman 1999; Reich 2002; Coleman et al. 2004).

Multi-species plant studies, aiming at distinguishing between biomass allocation changes that result from ontogenetic drift and true adjustment, are scarce in tropical climates, particularly in the context of the afforestation of degraded drylands. This is partly because the required sequential sampling of $\mathrm{AGB}$ and $\mathrm{BGB}$ is challenging in open-field research (Robinson 2004). We assessed biomass allocation patterns in five afforestation species grown on degraded cropland under varying levels of nutrients and water supply during early stand development in Northern Benin, West Africa. Three of the tested species (Leucaena leucocephala Lam., Moringa oleifera Lam., and J. curcas) were previously classified as fast-growing and two (Anacardium occidentale L. and $P$. biglobosa) as slow-growing species, based on the response of root-level and shoot-level morphological traits to nutrient and water amendments (Noulèkoun et al. 2017). Yet, the previous studies did not address the dynamics of plant aboveground and belowground responses to silvicultural treatments with emphasis on biomass production and allocation. We hypothesized that (i) increased resource availability boosts biomass production significantly more in species characterized by faster ontogenetic development than in slow growers, (ii) biomass partitioning to belowground decreases with ontogeny, and (iii) when ontogeny is accounted for as a function of plant size, increasing resource availability triggers greater biomass allocation to aboveground versus belowground.

\section{Materials and methods}

\subsection{Study site description}

The study site, plant materials, and experimental design were previously described in detail by Noulèkoun et al. (2017). The research was carried out in Pouri village (N $10^{\circ} 54^{\prime} 8.4^{\prime \prime}$ and E $\left.1^{\circ} 4^{\prime} 47.4^{\prime \prime}\right)$ located on the periphery of the Dassari catchment in the department of Atacora, Northern Benin. The area is 
characterized by a semi-arid climate, marked by one dry season (November to March) with temperatures rising as high as $45^{\circ} \mathrm{C}$ and one rainy season (April to October) with temperatures falling to $14{ }^{\circ} \mathrm{C}$. The average annual precipitation for the 15-month study period, spanning the 2014 and 2015 rainy (growing) seasons, was $795 \mathrm{~mm}$. The vegetation is typical for a Sudan savanna ecological zone, with parklands, forest patches, and agricultural and fallow land, all of which are impacted by human activity (Saïdou et al. 2004; Chabi et al. 2016). The soils are compacted, limited in their depth by gravel and lateritic formations, and have low to moderate inherent fertility (Saïdou et al. 2004; Azuka et al. 2015). The soil at the research site was classified as an epipetric plinthosol with sandy-loamy texture in the surface layer and loamy soil dominated by clayey loam in deeper layers. Total carbon and NPK measured $0.5 \%, 0.1 \%, 1.2 \mathrm{mg} \mathrm{kg}^{-1}$, and $44.3 \mathrm{mg} \mathrm{kg}^{-1}$, respectively.

\subsection{Woody species}

The afforestation trial established at the degraded cropping site in July 2014 included five (semi-)deciduous tree species that differed in terms of their growth potential and tolerance to drought (Noulèkoun et al. 2017): the fast-growing Moringa oleifera Lam. (drumstick tree, Moringaceae), Jatropha curcas L. (physic nut, Euphorbiaceae), and Leucaena leucocephala Lam. (leucaena, Fabaceae) and the slow-growing Anacardium occidentale L. (cashew, Anacardiaceae) and Parkia biglobosa Jacq. (African locust bean, Fabaceae). Seeds were germinated in a local nursery and planted at the experimental site after 2.5-4 months.

\subsection{Experimental design}

Three experimental factors were considered to influence plant growth and biomass production and allocation: (i) the five species and two silvicultural treatments consisting of (ii) drip irrigation and (iii) fertilization by manuring. The species and irrigation variables were subject to a fully factorial design with three repetitions, while manuring was nested within plots. The design thus consisted of a total of 30 pure species plots, each $12 \times 8 \mathrm{~m}^{2}$ in size. Each plot contained 48 seedlings spaced at $2 \times 1 \mathrm{~m}$, resulting in an initial density of 5000 plants ha $^{-1}$.

The irrigation and fertilization treatments resulted in four resource management options: no resource manipulation (control, C), irrigation (I), fertilization (F), and irrigation plus fertilization (IF). An adapted drip irrigation system (Fig. 1) was used during the dry season to supply $0.5 \mathrm{~L}$ of water per sapling daily to meet $30 \%$ of the evaporative demand (Allen et al. 1998). This amounted to a total of $72.5 \mathrm{~mm}$ of irrigation. In addition, saplings received $33 \mathrm{~mm}$ of rainfall during the 2014-2015 dry season. Manure was supplied in the amount of $1 \mathrm{~kg}$ per plant in both growing seasons, i.e., at 2.5 and
11 months after planting (MaP). The manure was composted cow and pig dung and contained on average $18.7 \%$ carbon (C), $1.2 \%$ nitrogen $(\mathrm{N})$, and $0.8 \%$ phosphorus $(\mathrm{P})$.

\subsection{Biomass production}

Plants were sampled at 5, 11, and $15 \mathrm{MaP}$, representing the first growing (rainy) season (0-5 MaP), the subsequent dry season (5-11 MaP), and the second growing season (11-15 $\mathrm{MaP}$ ). At each sampling, two to six saplings were randomly selected from each experimental plot and harvested entirely. The plants were felled, and the AGB separated into leaves (including the petiole), stems with branches, and (if present) reproductive parts. Roots were manually excavated and sectioned into coarse $(\varnothing>2 \mathrm{~mm})$ and fine $(\varnothing<2 \mathrm{~mm})$ fractions. The roots were gently washed on a sieve and freed of soil. The fresh mass of each fraction was recorded in the field using a 7 $\mathrm{kg}$ portable scale (accuracy $0.1 \mathrm{~g}$ ) and oven-dried at $75^{\circ} \mathrm{C}$ until a constant weight. Woody samples were cut into small pieces before oven drying.

At $11 \mathrm{MaP}$, biomass was also sampled from a 10-year-old natural fallow, located in the vicinity of the experiment to compare biomass productivity between afforested (active intervention) and fallowed (natural succession) sites. An area of 0.5 ha was delineated in the fallow land where three sub-plots of $4 \times 4 \mathrm{~m}$ each were installed along one of the diagonals for sampling. Grazing was not controlled. The AGB and BGB of the predominant vegetation, consisting of shrubs (e.g., Combretum glutinosum) and trees (e.g., Terminalia macroptera), were quantified for each species and sub-plot as described above.

\subsection{Statistical analyses of treatments}

A linear mixed-effect model was used to assess the effects of the abovementioned experimental factors on biomass production at 5, 11, and $15 \mathrm{MaP}$. The effect of irrigation was tested at 11 and $15 \mathrm{MaP}$. The statistical analyses consisted of several steps. First, the effects of species, treatment $(\mathrm{F}$ and $\mathrm{I})$, and treatment interaction on total biomass production were tested. Second, differences observed between the species in biomass production with respect to the silvicultural treatments were analyzed. Species, fertilization, and irrigation were considered as fixed terms, while plot identity and fertilization (nested within plots) as random terms. The robust variance estimates and unstructured covariance options in STATA 14 (StataCorp 2015) were used to control for any deviation from the assumption of normality in the data. A least significance difference (LSD) test was used to compare means when significant treatment effects were found. 
Fig. 1 Drip system using local 1.5-L plastic bottles for the supplemental irrigation of saplings during the dry season (December 2014-May 2015) at the afforestation site in Northern Benin

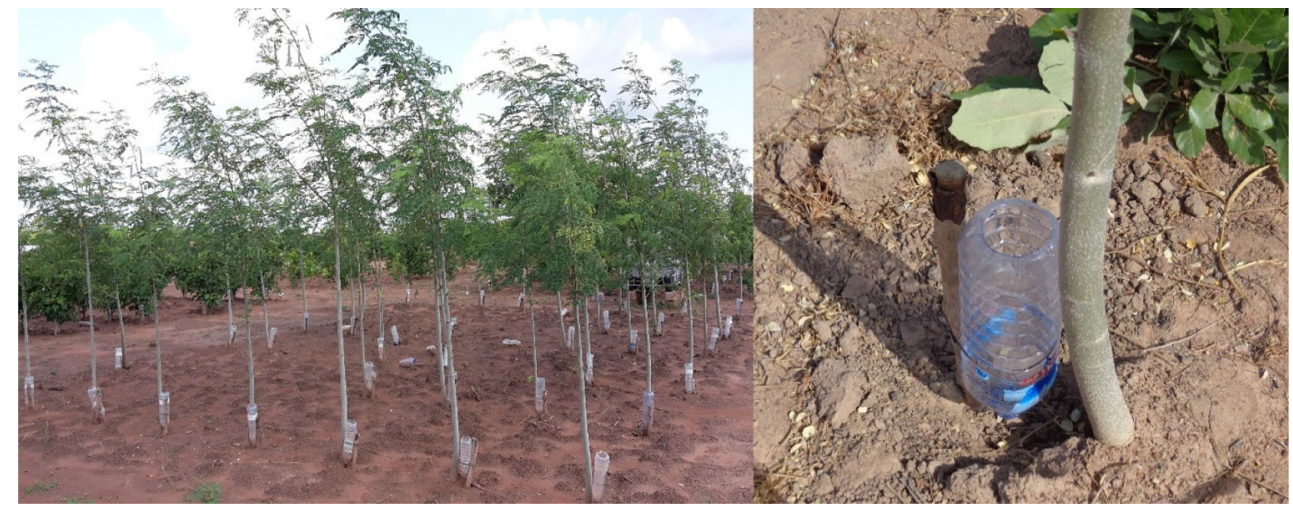

\subsection{Relative biomass allocation analysis}

The effect of the treatments and ontogeny on biomass allocation was evaluated using clasmometric and allometric analyses (Poorter and Sack 2012). For the clasmometric analysis, the root mass fraction (RMF) was computed and plotted against the natural log-transformed estimate of the whole-plant dry biomass, which was used as a reference for the ontogenetic stage (e.g., Evans 1972; Poorter and Pothmann 1992; Poorter and Sack 2012). The allometric analysis was performed using an approach that allows for the differentiation between the effects of ontogeny and resource availability on biomass allocation (Hunt 1978; Coleman et al. 2004):

$\ln Y=a+k \ln X$

where $Y$ is the total root (coarse and fine) dry mass, $X$ is the total shoot (leaf and stem) dry mass, $a$ is the y intercept, and the slope $k$ is the allometric coefficient. The greater the value of $k$, the greater the biomass allocation to the roots relative to the shoots. If $k$ is similar between the treatments, any shift in biomass allocation can be attributed to development (Hunt 1978). An analysis of covariance (ANCOVA) was used to reveal differences in $k$ between treatments. The ANCOVA consisted of fitting the model in Eq. 1 to the treatment class variable. A significant interaction between the covariates (natural log-transformed stand-level estimates of root and shoot dry mass) and the treatment variable is considered indicative of a treatment-induced shift in biomass allocation. An ANCOVA was also used to compare the RMF versus tree size relationship between the treatments as revealed by clasmometry. In the case of significant interactions between the covariate and treatment factor, an LSD post hoc test was used to compare the slopes. In the case of equality of slopes between the treatments, a test of differences in intercepts was additionally performed. Following Niklas and Enquist (2002) and Poorter et al. (2015), the reproductive biomass fractions (fruits of $J$. curcas and pods of M. oleifera), which represented $2-5 \%$ of the total biomass, were omitted from the analyses.
To further assess the relative explanatory power of ontogeny and treatment effects on biomass allocation, stepwise multiple regression was conducted to characterize the effect of total dry mass, fertilization, and irrigation on root dry mass separately for each species. The natural logtransformed mass values and their residuals were judged to be normally distributed and homoscedastic based on a combination of histograms and normality tests performed in STATA 14. Data from the three harvests at the experimental site were pooled to account for changes in biomass allocation over the full size range (Poorter et al. 2012; Poorter and Sack 2012).

\section{Results}

\subsection{Biomass production}

\subsubsection{Effects of resource supply}

The shoot, root, and total biomass were affected by fertilization and irrigation, but the effects differed between species and assessment periods (Table 1). At $5 \mathrm{MaP}$, total biomass increased due to fertilization (F) compared to the control (C) by $18 \%$ in M. oleifera, $23 \%$ in J. curcas, and $25 \%$ in L. leucocephala. No significant difference in biomass accumulation was observed between the $\mathrm{C}$ and $\mathrm{F}$ treatments for A. occidentale and P. biglobosa saplings, which were the smallest in size (Figs. 2a and 3a, Supplementary material, Appendix S1). The fertilizer-related biomass increase in fastgrowing species was mirrored predominantly in AGB accumulation (Fig. 2, Supplementary material, Appendix S1). At the end of the dry season (11 MaP), only the slow-growing species responded to treatments (Table 1, Supplementary material, Appendix S1). Both A. occidentale and $P$. biglobosa saplings accumulated greater root biomass under $\mathrm{IF}$ and $\mathrm{F}$ compared to $\mathrm{C}$ at this point in time (Fig. 2b). The continued growth during the dry season substantially enhanced total biomass accumulation in P. biglobosa, which increased by $176 \%$ under IF and by $335 \%$ under F compared 
Table 1 Significance of species, fertilization, irrigation, and fertilization $x$ irrigation factors for aboveground and belowground biomass production after the first growing season $(0-5 \mathrm{MaP})$, the dry season (5$11 \mathrm{MaP}$ ), and the second growing season (11-15 MaP) for plantations of M. oleifera, J. curcas, L. leucocephala, A. occidentale, and P. biglobosa on degraded cropland in Northern Benin. $P$ values lower than $\alpha=0.05$ are indicated in italics

\begin{tabular}{lrrr}
\hline Factors & Shoot $^{\mathrm{a}}$ & \multicolumn{1}{c}{ Root $^{\mathrm{b}}$} & Total $^{\mathrm{c}}$ \\
\hline $5 \mathrm{MaP}$ & & & \\
Species (S) & $<0.001$ & $<0.001$ & $<0.001$ \\
Fertilization (F) & $<0.001$ & 0.002 & $<0.001$ \\
$\mathrm{~S} \times \mathrm{F}$ & 0.002 & 0.021 & 0.005 \\
$11 \mathrm{MaP}$ & & & \\
Species (S) & $<0.001$ & $<0.001$ & $<0.001$ \\
Fertilization (F) & 0.549 & 0.915 & 0.677 \\
$\mathrm{~S} \times \mathrm{F}$ & 0.579 & $<0.001$ & 0.035 \\
Irrigation (I) & 0.918 & 0.716 & 0.838 \\
$\mathrm{~S} \times \mathrm{I}$ & 0.403 & 0.109 & 0.354 \\
$\mathrm{~F} \times \mathrm{I}$ & 0.873 & 0.019 & 0.583 \\
$\mathrm{~S} \times \mathrm{F} \times \mathrm{I}$ & 0.082 & $<0.001$ & $<0.001$ \\
$15 \mathrm{MaP}$ & & & \\
Species (S) & $<0.001$ & $<0.001$ & $<0.001$ \\
Fertilization (F) & $<0.001$ & $<0.001$ & $<0.001$ \\
$\mathrm{~S} \times \mathrm{F}$ & $<0.001$ & $<0.001$ & $<0.001$ \\
Irrigation (I) & 0.183 & 0.827 & 0.281 \\
$\mathrm{~S} \times \mathrm{I}$ & $<0.001$ & $<0.001$ & $<0.001$ \\
$\mathrm{~F} \times \mathrm{I}$ & 0.253 & 0.002 & 0.114 \\
$\mathrm{~S} \times \mathrm{F} \times \mathrm{I}$ & 0.832 & 0.104 & 0.711 \\
\hline $\mathrm{S}$ & & &
\end{tabular}

${ }^{\text {a }}$ Shoot $=$ leaves + stem; reproductive parts were not included

${ }^{\mathrm{b}}$ Root $=$ coarse roots + fine roots

${ }^{\mathrm{c}}$ Total $=$ shoot + root

to $\mathrm{C}$. In contrast, the total biomass of the fast-growing species declined between 5 and $11 \mathrm{MaP}$ mainly due to a loss of shoot biomass (Fig. 2b). At the end of the second growing season (15 MaP), total biomass followed the order F $>$ IF $>$ I $>$ C for the fast growers, although the differences between treatments were not statistically significant in all cases (Fig. 2c). For the slow growers, the pattern of treatment effects on total biomass followed the order of $\mathrm{IF}=\mathrm{F}=\mathrm{I}>\mathrm{C}$. The range of the increase in total biomass under $\mathrm{F}$ compared to $\mathrm{C}$ was substantially greater $(8-335 \%)$ in the slow growers compared to that in the fast-growing species (19-68\%). A significant effect of second-order interactions (e.g., species $\times$ fertilization $\times$ irrigation) was observed on root and total biomass at $11 \mathrm{MaP}$ only (Table 1) but resulted from differential responses of fastgrowing and slow-growing species to treatments (Fig. 2).

Fertilization consistently affected every biomass component at 5 and $15 \mathrm{MaP}$. Conversely, the overall effect of irrigation was marginal. It was much more evident at $15 \mathrm{MaP}$ and varied greatly between species (Table 1, Fig. 2).

\subsubsection{Species differences}

At $5 \mathrm{MaP}$, the species ranking in terms of total biomass accumulation followed the order $M$. oleifera $>J$. curcas $>$ L. leucocephala $>$ A. occidentale $>$ P. biglobosa (Fig. 3a). Shoot biomass ranking followed the same order, but the root biomass was similar for $A$. occidentale and P. biglobosa. At 11 $\mathrm{MaP}$, total biomass did not significantly differ between $M$. oleifera and L. leucocephala and between J. curcas and A. occidentale (Fig. 3b). At $15 \mathrm{MaP}$, L. leucocephala accumulated significantly greater total biomass than the other four species while $A$. occidentale and particularly P. biglobosa accumulated the lowest total biomass (Fig. 3c). For instance, total biomass in L. leucocephala was $53 \%$ greater than in M. oleifera, $183 \%$ greater than in A. occidentale, and $659 \%$ greater than in P. biglobosa. Shoot and root biomass followed a similar pattern (Fig. 3c). The total biomass on the 10-year-old fallow land was estimated at $19.98 \mathrm{Mg} \mathrm{ha}^{-1}$.

\subsection{Biomass allocation}

\subsubsection{Effects of resource supply}

For all species and treatments, the RMF fell (slope $<0$, Fig. 4) with increasing tree size, reflecting ontogenetic drift, except in A. occidentale, which demonstrated no significant change $(P=$ 0.68 , Table 2, Fig. 4f). The decrease in RMF was influenced by the F and I treatments (Supplementary material, Appendix S2), but this exhibited great variation and was species specific (Fig. 4). For M. oleifera, the decline in the RMF was larger in saplings under $\mathrm{C}$, I, and IF than in those under F, whereas a greater decrease occurred in L. leucocephala saplings under IF and I compared to $\mathrm{C}$ and $\mathrm{F}$ treatments (Table 2, Fig. 4a, c). However, treatment had no effect on the RMF in J. curcas, A. occidentale, or P. biglobosa $(P>0.05$; Table 2$)$.

Allometric analysis revealed significant and strong linear relationships $\left(R^{2}>0.8\right)$ between root and shoot biomass (Table 3 ). For J. curcas, L. leucocephala, and A. occidentale, the variations in biomass allocation to belowground between treatments were all explained by ontogeny, as evidenced by a $k$ that did not significantly differ between treatments (Table 3 ). The rate of increase in root biomass with increasing shoot biomass (i.e., $k$ ) did not differ $(P>0.05)$ between treatments for $P$. biglobosa, but the intercept was significantly higher for saplings grown under $\mathrm{C}$ and I compared to $\mathrm{F}$ and IF $(P=0.038$; data not shown). Conversely, $M$. oleifera exhibited a significantly higher $k$ under both $\mathrm{F}$ and IF compared to $\mathrm{C}$ and I treatments (Table 3), indicating that the treatments altered belowground allocation in this species. Due to the differing patterns of treatment-induced effects on the allometric relationship, the relative variation explained by ontogeny and by fertilization and irrigation was further distinguished. The ontogeny was always important in the allometric relationship between roots and shoots, explaining 86 
Fig. 2 Aboveground (leaves and stem) and belowground (coarse and fine roots) biomass of five woody species at a $5 \mathrm{MaP}, \mathbf{b} 11$ $\mathrm{MaP}$, and $\mathbf{c} 15 \mathrm{MaP}$ on degraded cropland in Northern Benin. Treatments included control (C), fertilization (F), irrigation (I), and irrigation + fertilization (IF). The "zero" line on the $y$-axis delineates the ground surface. Vertical bars are standard errors of the mean. Lowercase letters above the bars denote shoots and those below the bars roots. Capital letters relate to total biomass. For each species, means with different letters indicate the significant impact of the treatment according to a LSD post hoc test $(\alpha=0.05)$
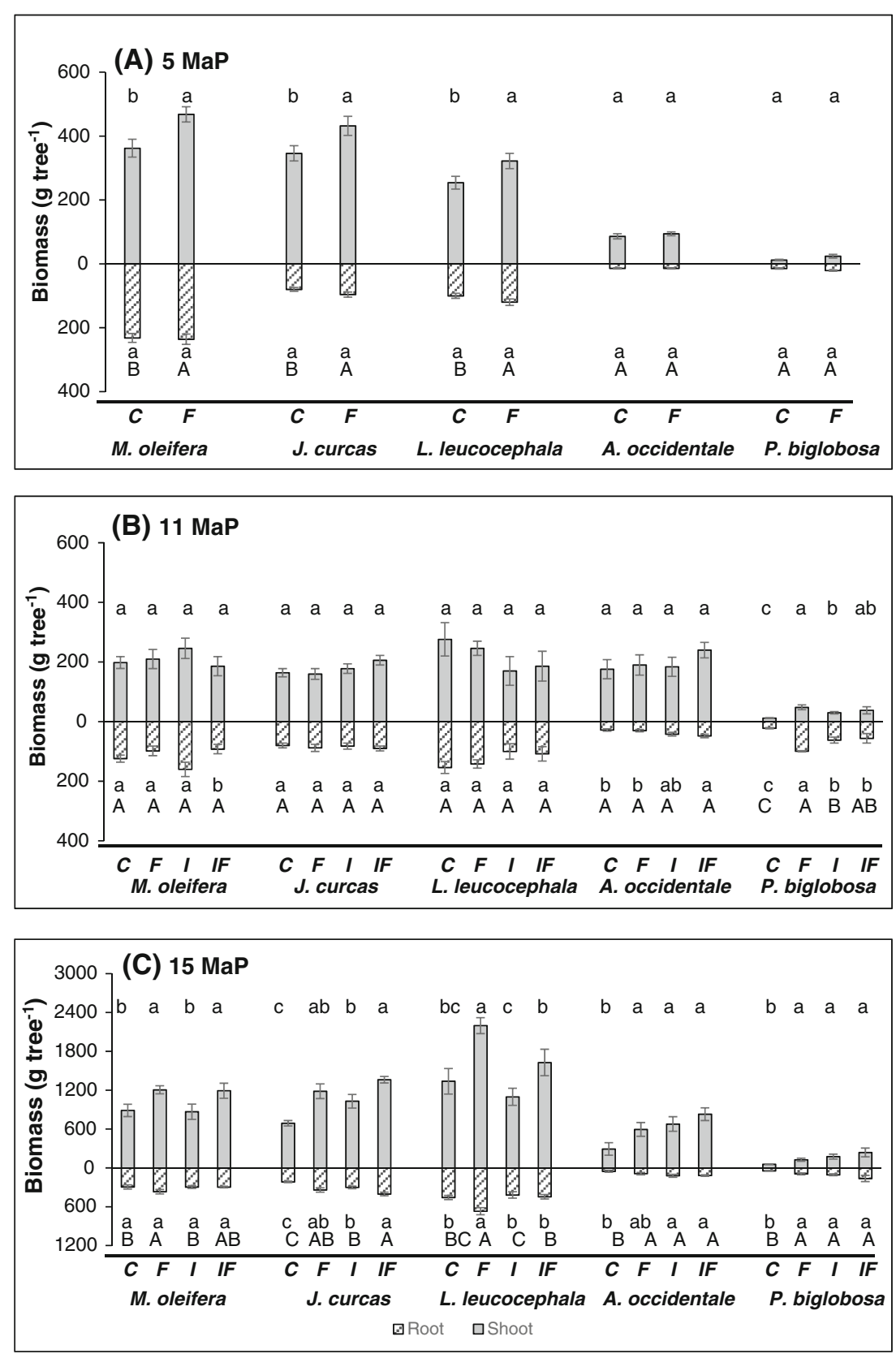

$95 \%$ of the variation in all species $(P<0.001$, Table 4$)$. The amount of variation in the root versus shoot allocation explained by fertilization was $0.3-0.7 \%$ and that by irrigation $1.4-43 \%$. Neither factor appeared significant in the models (Table 4).

\subsubsection{Species differences}

Of the species selected for this study, the RMF was the highest in $P$. biglobosa, ranging between 30 and $75 \%$ of the total biomass over the entire size range (Fig. 4f). The proportion of total biomass allocated to belowground was $<50 \%$ in M. oleifera, J. curcas, and L. leucocephala and $<30 \%$ in A. occidentale. The latter had the highest $k$ value of the five species, which was close to unity (a mean of 0.98 with a $95 \%$ confidence interval between 0.9 and 1.06, Table 3). The $k$ values averaged $0.66 \pm 0.09,078 \pm 0.08,0.78 \pm 0.07$, and $0.75 \pm 0.07$ for M. oleifera, J. curcas, L. leucocephala, and P. biglobosa, respectively (Table 3 ).

\section{Discussion}

\subsection{Silvicultural treatment effects}

The addition of manure and supplemental irrigation generally increased biomass production in the multi-species 
Fig. 3 Mean aboveground (leaves and stem) and belowground (coarse and fine roots) biomass across treatments for five woody species at a $5 \mathrm{MaP}$, b $11 \mathrm{MaP}$, and c $15 \mathrm{MaP}$ on degraded cropland in Northern Benin. Treatments and symbols are as in Fig. 2
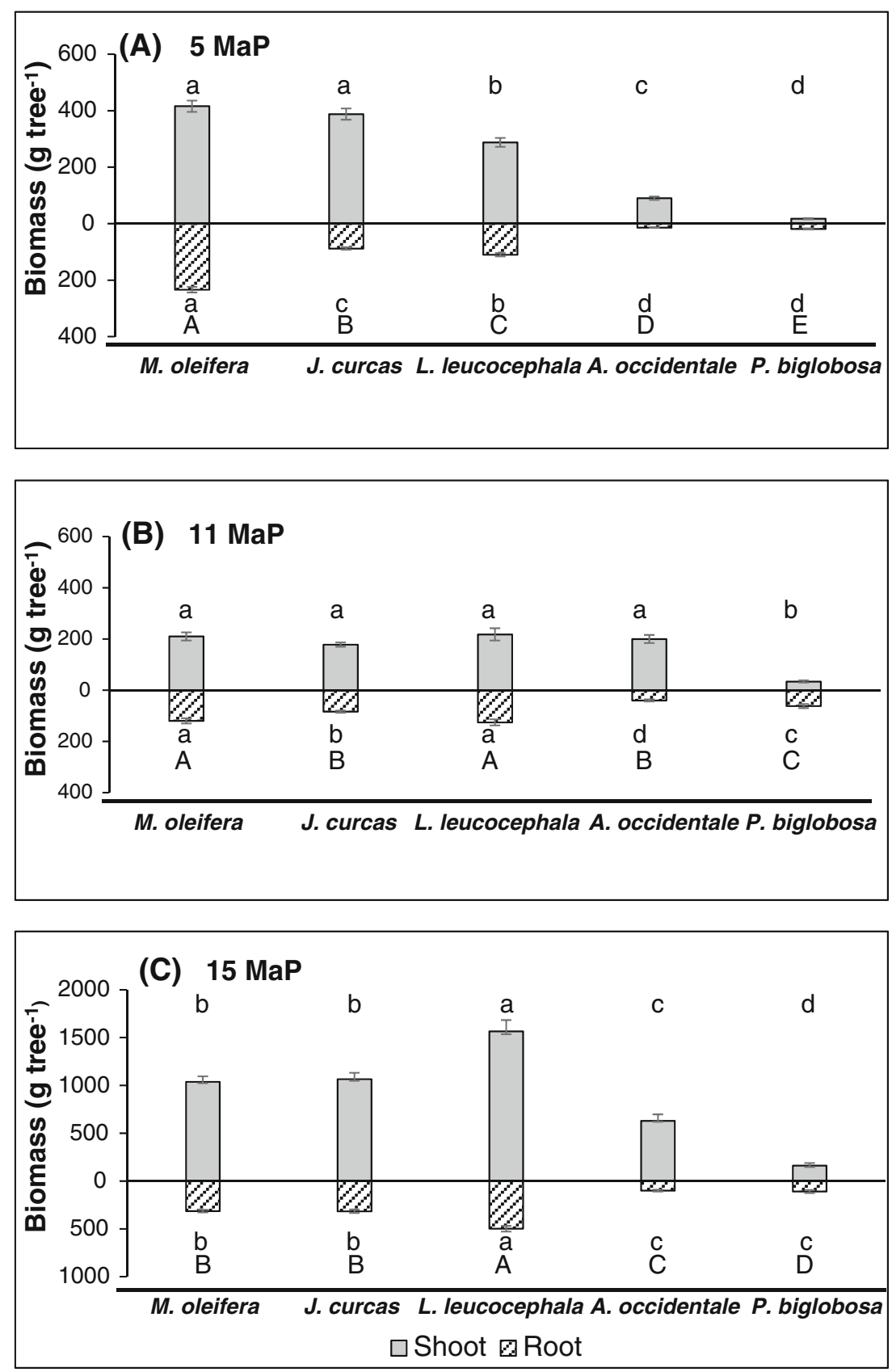

afforestation system. During the earliest stage of development (0-5 MaP) and in the second growing season (11-15 MaP), increased nutrient availability led to greater aboveground and total biomass accumulation but in M. oleifera, J. curcas, and L. leucocephala only. This confirms our hypothesis that increased resource availability has a more positive effect on the biomass production of fast-growing species than it does on slow-growing species. The higher sensitivity of the three fast-growing species to the experimental treatments is likely a result of their exploitative use of resources (Reich et al. 2003; Reich 2014; Noulèkoun et al. 2017). In contrast, both slow-growing species were responsive to silvicultural practices during the dry season $(5-11 \mathrm{MaP})$, which is in line with the hypothesis that increased resource availability also increases biomass production in slow growers. Fertilization and irrigation led to greater total biomass accumulation in $P$. biglobosa and to an increase in BGB in A. occidentale saplings receiving I and IF (Fig. 2b). Slow-growing species perform better when resources are scarce because of their conservative use of resources (Reich et al. 2003; Reich 2014; Noulèkoun et al. 2017), which explains the differences observed in the response to the treatments by the fast-growing and slow-growing species during the dry season.

Of the five species, L. leucocephala produced the greatest total biomass $\left(2.1 \mathrm{~kg}\right.$ tree $\left.{ }^{-1}\right)$ at $15 \mathrm{MaP}$ on the degraded cropland, with the total biomass of manured L. leucocephala 
Fig. 4 Fractional allocation to roots (RMF) relative to total sapling dry mass for $M$. oleifera (a), J. curcas (b), L. leucocephala (c), A. occidentale (d),

P. biglobosa (e), and all species combined (f) in response to the control (C), fertilization (F), irrigation (I), and fertilization + irrigation (IF). Total dry mass values were natural logtransformed. Data from three harvests $(5,11$, and $15 \mathrm{MaP})$ are considered

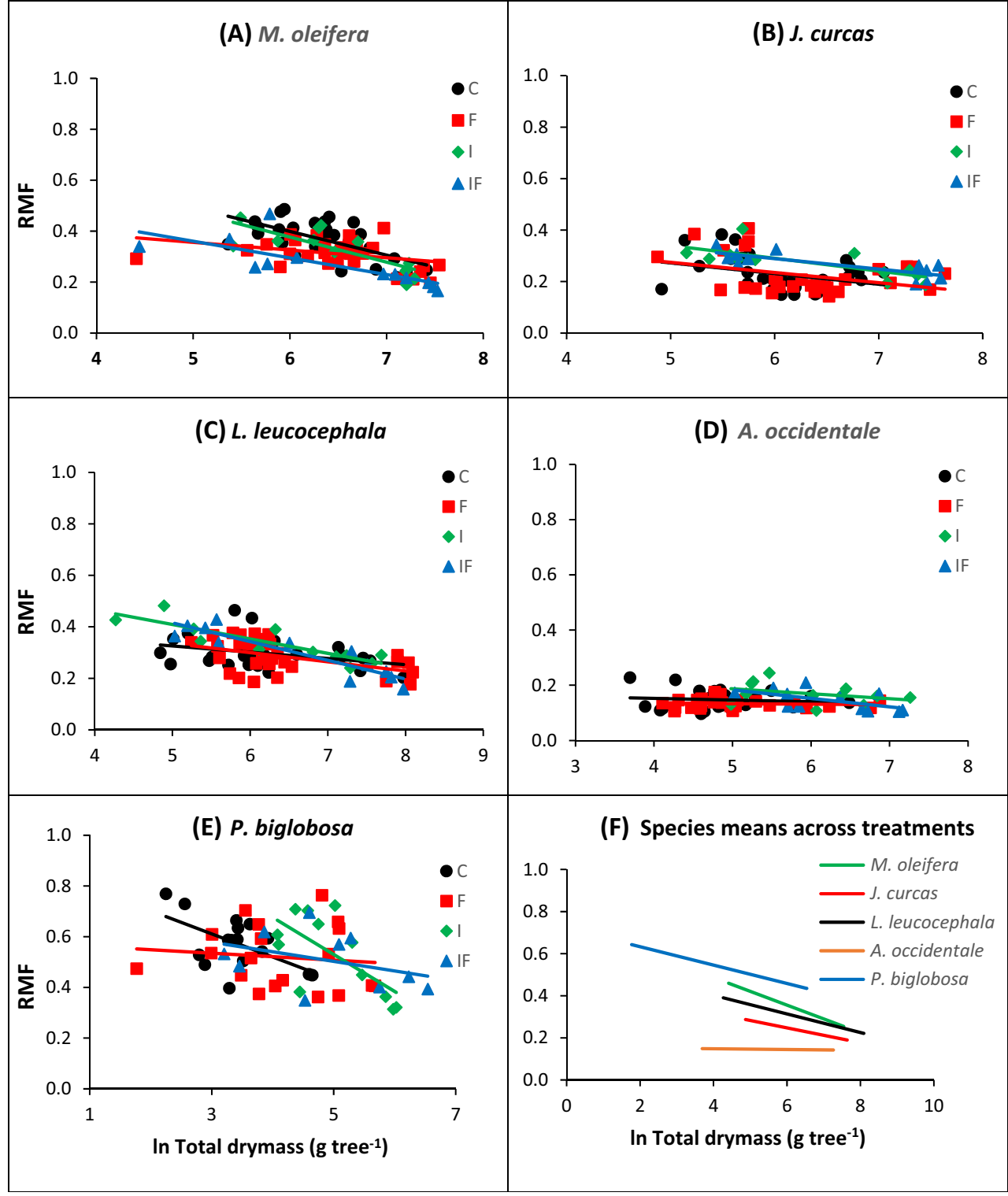

saplings almost doubling that of $M$. oleifera and $J$. curcas (Figs. 2c and 3c). This demonstrates the strong potential of this species in afforestation schemes. The leguminous L. leucocephala, known as a "fertilizer tree," has been recommended for the restoration of impoverished lands (Garrity et al. 2010). In addition, we found that manuring boosted the biomass production of L. leucocephala, possibly due to the increased supply of $\mathrm{P}$, which enhances $\mathrm{N}_{2}$
Table 2 Slope comparison for the relationship between the fractional allocation to roots (RMF) and total dry mass for five woody species under the control (C), fertilization (F), irrigation (I), and fertilization + irrigation (IF) treatments

\begin{tabular}{llllll}
\hline Treatment & M. oleifera & J. curcas & L. leucocephala & A. occidentale & P. biglobosa \\
\hline Control (C) & $-0.093 \mathrm{~b}$ & $-0.041 \mathrm{a}$ & $-0.024 \mathrm{~b}$ & $-0.006 \mathrm{a}$ & $-0.091 \mathrm{a}$ \\
Fertilization (F) & $-0.030 \mathrm{a}$ & $-0.039 \mathrm{a}$ & $-0.036 \mathrm{~b}$ & $-0.002 \mathrm{a}$ & $-0.014 \mathrm{a}$ \\
Irrigation (I) & $-0.099 \mathrm{~b}$ & $-0.049 \mathrm{a}$ & $-0.056 \mathrm{ab}$ & $-0.018 \mathrm{a}$ & $-0.146 \mathrm{a}$ \\
Fertilization + irrigation (IF) & $-0.065 \mathrm{ab}$ & $-0.041 \mathrm{a}$ & $-0.073 \mathrm{a}$ & $-0.031 \mathrm{a}$ & $-0.038 \mathrm{a}$ \\
Mean across treatments & $-0.066 \mathrm{~B}$ & $-0.035 \mathrm{~B}$ & $-0.044 \mathrm{~B}$ & $-0.002 \mathrm{~A}$ & $-0.044 \mathrm{~B}$ \\
\hline
\end{tabular}

Within columns and for treatments, values followed by the same lowercase letter are not significantly different. Within a row, species means followed by the same uppercase letter are not significantly different. For all the cases of equal slopes between the treatments, the comparison of the intercepts showed no significant difference (data not shown). A significance level of $P<0.05$ was used for the LSD post hoc test 
Table 3 Allometric coefficients $(k)$ and coefficient of determination $\left(R^{2}\right)$ for the root and shoot relationship of five woody species under the control (C), fertilization (F), irrigation (I), and fertilization + irrigation (IF) treatments

\begin{tabular}{llllll}
\hline Treatments & M. oleifera & J. curcas & L. leucocephala & A. occidentale & P. biglobosa \\
\hline Control (C) & $0.564 \mathrm{~b}$ & $0.721 \mathrm{a}$ & $0.855 \mathrm{a}$ & $0.965 \mathrm{a}$ & $0.593 \mathrm{a}$ \\
Fertilization (F) & $0.814 \mathrm{a}$ & $0.755 \mathrm{a}$ & $0.803 \mathrm{a}$ & $0.982 \mathrm{a}$ & $0.821 \mathrm{a}$ \\
Irrigation (I) & $0.561 \mathrm{~b}$ & $0.747 \mathrm{a}$ & $0.764 \mathrm{a}$ & $0.866 \mathrm{a}$ & $0.428 \mathrm{a}$ \\
Fertilization + irrigation (IF) & $0.674 \mathrm{ab}$ & $0.793 \mathrm{a}$ & $0.667 \mathrm{a}$ & $0.741 \mathrm{a}$ & $0.799 \mathrm{a}$ \\
Mean across treatments & $0.658 \mathrm{C}$ & $0.785 \mathrm{~B}$ & $0.777 \mathrm{~B}$ & $0.981 \mathrm{~A}$ & $0.751 \mathrm{AB}$ \\
$R^{2}$ & 0.836 & 0.812 & 0.918 & 0.942 & 0.851 \\
\hline
\end{tabular}

Within columns and for treatments, values followed by the same lowercase letter are not significantly different. Within a row, species means followed by the same uppercase letter are not significantly different. For $J$. curcas, L. leucocephala, and A. occidentale, the comparison of intercepts between the treatments showed no significant difference. Intercepts were significantly different between the treatments for P. biglobosa (data not shown). A significance level of $P<0.05$ was used for the LSD post hoc test fixation in trees growing in P-poor agricultural soil (Djumaeva et al. 2013).

The limited response to irrigation during the dry season can be attributed to (i) a greater importance of nutrient over water stress under semi-arid conditions (Reubens et al. 2011; Noulèkoun et al. 2017), (ii) the relatively low amount of water supplied per plant during the dry season, and (iii) the deciduousness of the tree species as a drought-escaping mechanism inducing dormancy during dry periods (e.g., Monasterio and Sarmiento 1976; Reich and Borchert 1984; Poorter and Markesteijn 2008). In the fast-growing species, the deciduousness also caused a decrease in biomass accumulation between 5 and $11 \mathrm{MaP}$. However, the effect of supplemental irrigation may extend beyond the dry season period in which it was applied, as shown by the enhanced longitudinal and cambial growth of shoots and roots in same trial at $15 \mathrm{MaP}$ (Noulèkoun et al. 2017), the extended photosynthetically active period in coppicing trees in South Africa (Moyo et al. 2015), and the overall rise in AGB production in a long-term afforestation trial in arid Uzbekistan (Khamzina et al. 2008). This post-irrigation effect was particularly evident in the slow growers, which exhibited comparable total biomass production under the I, F, and IF treatments at $15 \mathrm{MaP}$ (Fig. 2c).

\subsection{Biomass allocation as influenced by ontogeny and resource availability}

Previous studies aiming to understand the effects of increased resource availability on biomass allocation in deciduous species (Achten et al. 2010) and conifers (Coyle and Coleman 2005) have reported conflicting results, presumably because the impact of ontogeny was not always considered (McCarthy and Enquist 2007). In our study, except for A. occidentale, the RMF dropped for all species and across all treatments over time (Fig. 3 and $k<1$, Table 3 ), confirming that the partitioning of biomass to belowground was predominantly controlled by ontogeny (Table 4). Similar ontogenetically induced falls in the RMF have been reported for seedlings (Coleman et al. 1998) and 3-4-year-old plantations of loblolly
Table 4 Multiple regression parameters according to tree species demonstrating the relative importance of ontogeny (total dry mass), fertilization, and irrigation for belowground biomass allocation. The dependent variable is root dry mass. A and B represent the intercept and slope of the robust linear regression

\begin{tabular}{|c|c|c|c|c|c|}
\hline Species & Independent variable & A & B & Prob $>F$ & Model $R^{2}$ \\
\hline \multirow[t]{3}{*}{ M. oleifera } & Total biomass & 0.299 & 0.775 & $<0.001$ & 0.861 \\
\hline & Fertilization & 5.335 & -0.089 & 0.458 & 0.007 \\
\hline & Irrigation & 5.331 & -0.143 & 0.336 & 0.014 \\
\hline \multirow[t]{2}{*}{ J. curcas } & Total biomass & -0.684 & 0.874 & $<0.001$ & 0.855 \\
\hline & Irrigation & 4.645 & 0.488 & 0.006 & 0.109 \\
\hline \multirow[t]{2}{*}{ L. leucocephala } & Total biomass & -0.278 & 0.849 & $<0.001$ & 0.945 \\
\hline & Irrigation & 5.027 & 0.242 & 0.242 & 0.019 \\
\hline \multirow[t]{3}{*}{ A. occidentale } & Total biomass & -1.903 & 0.991 & $<0.001$ & 0.944 \\
\hline & Fertilization & 3.347 & 0.097 & 0.656 & 0.003 \\
\hline & Irrigation & 2.973 & 1.251 & $<0.001$ & 0.427 \\
\hline P. biglobosa & Total biomass & -0.265 & 0.909 & $<0.001$ & 0.951 \\
\hline
\end{tabular}

Backward-stepwise selection was used to identify the most important independent variables. Multiple regression was then run to determine the relative variation explained by each. Data presented here are for the most important variables only 
pine and cottonwood genotypes (Coyle and Coleman 2005; Coyle et al. 2008) in humid sub-tropical climates.

After accounting for ontogeny (by comparing $k$ ), our results revealed either that there was no impact by I and $\mathrm{F}$ on biomass partitioning (e.g., in J. curcas and P. biglobosa) or that there was a shift toward greater root biomass (i.e., greater $k$ values) in nutrient-rich conditions (e.g., in M. oleifera). This indicates that resource availability has no consistent effect on BGB allocation in fast-growing and slow-growing species during early growth stages. The lack of consistent shifts in biomass allocation to belowground due to nutrient and water amendments, also evidenced by variations in the decrease in the RMF between treatments for $M$. oleifera and L. leucocephala (Table 2), has been reported earlier for grasses (McConnaughay and Coleman 1999; Reich 2002) and 3-yearold woody plants (Coyle and Coleman 2005). The evidence combined thus suggests that patterns in optimal biomass partitioning in relation to resource variation after controlling for size are variable and - to a large extent-unpredictable. According to OPT, a greater proportion of roots, the organs responsible for resource acquisition, is expected under lownutrient or low-moisture conditions (McConnaughay and Coleman 1999). This pattern was observed in M. oleifera (Fig. 4a), but the opposite occurred in $\mathrm{N}_{2}$-fixing L. leucocephala (Fig. 4c). Therefore, much of the variation in biomass partitioning explained by OPT is driven by differences in plant size and tree species rather than results from true plasticity in biomass allocation (McConnaughay and Coleman 1999; McCarthy and Enquist 2007).

The scaling slope $(k)$ of the allometric relationship between AGB and BGB was close to 1.0 for A. occidentale (Table 3). This finding is consistent with the allometric scaling theory (Enquist and Niklas 2002; Niklas and Enquist 2002), given that the relationship between root and shoot biomass is isometric over the considered size range (40-1400 g). In contrast, the scaling exponents for the other species were lower, ranging between 0.66 and 0.78 . This discrepancy between observation and theory could be due to the variation in biomass partitioning between aboveground and belowground as a consequence of species-specific adaptations to water-limited and nutrientlimited conditions (Enquist and Niklas 2002). It is also possible that there were systematic errors associated with excavating the entire rooting systems, leading to an underestimation of the root biomass (Robinson 2004) and thus reducing the numerical values of the scaling exponents (Niklas 2004).

\subsection{Implications for the afforestation of degraded croplands}

Trade-offs between rapid growth, resource utilization, and site adaptability arise when selecting suitable species for forest plantations (Aubrey et al. 2012). Fast-growing species are considered competitive but are narrow site adapted and require adequate resources to optimize productivity. Slow growers are more stress-tolerant and thus suitable to a broad range of environments (Aubrey et al. 2012). Of the five tested species, planting fast-growing $M$. oleifera, J. curcas, and $L$. leucocephala with an adequate nutrient supply has the highest production potential, as evidenced by their greater biomass production and strong positive response to fertilization (Fig. 2). This could increase return rates for investment in afforestation, but only for a limited expanse of plantation acreage due to the narrow site requirements of these species. In contrast, the slow-growing A. occidentale and P. biglobosa achieved reasonable biomass production and exhibited a more plastic response to treatments, as evidenced by the large range of treatment-induced increase in biomass. Considering the vast area of degraded croplands in SSA, afforestation using slow growers may produce a larger volume of biomass over the landscape as a whole. Overall then, a mixed cultivation of fast-growing and slow-growing species (Khamzina et al. 2006; Noulèkoun et al. 2017) seems to be most suitable for sustaining land cover.

The productivity of the 2-year-old afforestation site (5.8 $\mathrm{Mg} \mathrm{ha}^{-1}$ year $^{-1}$ ) was about three times greater than that of the 10-year-old fallow $\left(1.9 \mathrm{Mg} \mathrm{ha}^{-1}\right.$ year $\left.^{-1}\right)$. This comparative advantage of plantations over natural succession is due to both the silvicultural management in plantations and the slow regeneration and unsustainable grazing of fallow land.

\section{Conclusion}

Belowground biomass represented a substantial share (up to $77 \%$ ) of the total biomass of afforestation species in the early growth stages. However, with increasing tree size, a greater proportion of biomass was allocated to aboveground. Ontogeny rather than resource availability was the main driver of the observed shift in biomass partitioning. This implies that biomass allocation in young multi-species plantations can be captured by simple allometric coefficients, thereby improving predictions of growth models for young forest stands. On the other hand, increased resource availability through silvicultural treatment accelerated sapling biomass production, which overall led to the greater production of AGB. Fast-growing tree species produced more biomass, responding more vigorously to silvicultural treatments during the rainy seasons than did the slow growers. Significant treatment-induced increases in biomass and the ability to adjust production in resource-limited conditions were the key characteristics of slow-growing species. For these reasons, we suggest the use of both fast-growing and slow-growing tree species in the afforestation of degraded croplands.

Acknowledgements We thank the staff of WASCAL study catchment in Dassari and casual workers who helped during field work. Our sincere gratitude goes to Dr. Nadine Worou and Dr. Guido Lüchters who helped with the installation of the trial and data analysis, respectively. We are 
grateful to the editors and referees for their insightful and constructive comments.

Funding information This research was funded by the German Federal Ministry of Education and Research (BMBF) under the program WASCAL (West African Science Service Center on Climate Change and Adapted Land Use), project no. 00100218.

\section{Compliance with ethical standards}

Data availability This manuscript has data included as electronic supplementary material. The datasets generated and/or analyzed during the current study are available from the first or corresponding author on reasonable request.

Conflict of interest The authors declare that they have no conflict of interest.

\section{References}

Achten WMJ, Maes WH, Reubens B, Mathijs E, Singh VP, Verchot L, Muys B (2010) Biomass production and allocation in Jatropha curcas L. seedlings under different levels of drought stress. Biomass Bioenergy 34:667-676. https://doi.org/10.1016/j. biombioe.2010.01.010

Albaugh TJ, Allen HL, Dougherty PM, Kress LW, King JS (1998) Leaf area and above- and belowground growth responses of loblolly pine to nutrient and water additions. For Sci 44:317-328

Allen RG, Pereira LC, Raes D, Smith M (1998) Crop evapotranspiration (guidelines for computing crop water requirements), FAO Irrigation and Drainage Paper, vol 56. FAO, Rome, p 300

Aubrey DP, Coyle DR, Coleman MD (2012) Functional groups show distinct differences in nitrogen cycling during early stand development: implications for forest management. Plant Soil 351:219-236. https://doi.org/10.1007/s11104-011-0946-0

Azuka CV, Igué AM, Diekkrüger B, Igwe CA (2015) Soil survey and soil classification of the Koupendri catchment in Benin, West Africa. Afric J Agric Res 10:3938-3951. https://doi.org/10.5897/ AJAR2015.9904

Baumert S, Khamzina A, Vlek PLG (2016) Soil organic carbon sequestration in Jatropha curcas systems in Burkina Faso. Land Degrad Dev 27:1813-1819. https://doi.org/10.1002/ldr.2310

Bloom AJ, Chapin FS, Mooney HA (1985) Resource limitation in plants-an economic analogy. Annu Rev Ecol Evol Syst 16:363392. https://doi.org/10.1146/annurev.es.16.110185.002051

Brouwer R (1963) Some aspects of the equilibrium between over ground and underground plant parts. Jb Inst Biol Scheikundig Onder Landbouwgewassen 1963:31-39

Chabi A, Lautenbach S, Orekan VOA, Kyei-Baffour N (2016) Allometric models and aboveground biomass stocks of a West African Sudan Savannah watershed in Benin. Carbon Balance Manag 11:16. https://doi.org/10.1186/s13021-016-0058-5

Chamshama SAO, Nduwayezu JB (2002) Rehabilitation of degraded sub-humid lands in sub-Saharan Africa: a synthesis. Sokoine University of Agriculture, Morogoro

Coleman JS, McConnaughay KD, Ackerly DD (1994) Interpreting phenotypic variation in plants. Trends Ecol Evol 9:187-191. https://doi. org/10.1016/0169-5347(94)90087-6

Coleman MD, Dickson RE, Isebrands JG (1998) Growth and physiology of aspen supplied with different fertilizer addition rates. Physiol Plant 103:513-526. https://doi.org/10.1034/j.1399-3054.1998. 1030410.x
Coleman MD, Friend AL, Kern CC (2004) Carbon allocation and nitrogen acquisition in a developing Populus deltoides plantation. Tree Physiol 24:1347-1357. https://doi.org/10.1093/treephys/24.12. 1347

Coyle DR, Coleman MD (2005) Forest production responses to irrigation and fertilization are not explained by shifts in allocation. For Ecol Manag 208:137-152. https://doi.org/10.1016/j.foreco.2004.11.022

Coyle DR, Coleman MD, Aubrey DP (2008) Above and belowground biomass accumulation, production, and distribution of sweetgum and loblolly pine grown with irrigation and fertilization. Can J For Res 38:1335-1348. https://doi.org/10.1139/X07-231

Coyle DR, Aubrey DP, Coleman MD (2016) Growth responses of narrow or broad site adapted tree species to a range of resource availability treatments after a full harvest rotation. For Ecol Manag 362:107119. https://doi.org/10.1016/j.foreco.2015.11.047

de Graaff J, Kessler A, Nibbering JW (2011) Agriculture and food security in selected countries in sub-Saharan Africa: diversity in trends and opportunities. Food Sec 3:195-213. https://doi.org/10.1007/ s12571-011-0125-4

Djalilov B, Khamzina A, Hornidge AK, Lamers JPA (2016) Exploring constraints and incentives for the adoption of agroforestry practices on degraded cropland in Uzbekistan. J Environ Plan Manag 59:142162. https://doi.org/10.1080/09640568.2014.996283

Djumaeva D, Lamers JPA, Khamzina A, Vlek PLG (2013) The benefits of phosphorus fertilization of trees grown on salinized croplands in the lower reaches of Amu Darya, Uzbekistan. Agrofor Syst 87:555569. https://doi.org/10.1007/s10457-012-9576-7

Enquist BJ, Niklas KJ (2002) Global allocation rules for patterns of biomass partitioning in seed plants. Science 295:1517-1520. https:// doi.org/10.1126/science. 1066360

Evans GC (1972) The quantitative analysis of plant growth. Blackwell Scientific Publications, Oxford

Fening TM, Gershenzon J (2002) Where will the wood come from? Plantation forests and the role of biotechnology. Trends Biotechnol 20:291-296. https://doi.org/10.1016/S0167-7799(02)01983-2

Garrity DP, Akkinifesi FK, Ajayi OC, Weldesemayat SG, Mowo JG, Kalinganire A, Larwanou M, Bayala J (2010) Evergreen agriculture: a robust approach to sustainable food security in Africa. Food Sec 2: 197-214. https://doi.org/10.1007/s12571-010-0070-7

Hunt R (1978) Plant growth analysis. Edward Arnold Ltd., London 67 pp

Khamzina A, Lamers JPA, Worbes M, Botman E, Vlek PLG (2006) Assessing the potential of trees for afforestation of degraded landscapes in the Aral Sea Basin of Uzbekistan. Agrofor Syst 66:129 141. https://doi.org/10.1007/s10457-005-4677-1

Khamzina A, Lamers JPA, Vlek PLG (2008) Tree establishment under deficit irrigation on degraded agricultural land in the lower Amu Darya River region, Aral Sea Basin. For Ecol Manag 255:168178. https://doi.org/10.1016/j.foreco.2007.09.005

Khamzina A, Lamers JPA, Vlek PLG (2012) Conversion of degraded cropland to tree plantations for ecosystem and livelihood benefits. In: Martius C, Rudenko I, Lamers JPA, Vlek PLG (eds) Cotton, Water, Salts and Soums - Economic and Ecological Restructuring in Khorezm, Uzbekistan. Springer Science + Business Media, B.V., Dordrecht, pp 235-248

Lamers JPA, Khamzina A, Worbes M (2006) The analyses of physiological and morphological attributes of 10 tree species for early determination of their suitability to afforest degraded landscapes in the Aral Sea Basin of Uzbekistan. For Ecol Manag 221:249-259. https://doi.org/10.1016/j.foreco.2005.10.022

McCarthy MC, Enquist BJ (2007) Consistency between an allometric approach and optimal partitioning theory in global patterns of plant biomass allocation. Funct Ecol 21:713-720. https://doi.org/10.1111/ j.1365-2435.2007.01276.x

McConnaughay KDM, Coleman JS (1999) Biomass allocation in plants: ontogeny or optimality? A test along three resource gradients. 
Ecology 80:2581-2593. https://doi.org/10.1890/0012-9658(1999) 080[2581:BAIPOO]2.0.CO;2

Mead DJ (2013) Sustainable management of Pinus radiata plantations. FAO Forestry paper 170. Food and Agriculture Organization of the United Nations, Rome

Mokany K, Raison RJ, Prokushkin AS (2006) Critical analysis of root: shoot ratios in terrestrial biomes. Glob Chang Biol 12:84-96. https:// doi.org/10.1111/j.1365-2486.2005.001043.x

Monasterio M, Sarmiento G (1976) Phenological strategies of plant species in the tropical savanna and the semi-deciduous forest of the Venezuelan Llanos. J Biogeogr 3:325-355. https://doi.org/10. 2307/3037976

Moyo H, Scholes MC, Twine W (2015) Effects of water and nutrient additions on the timing and duration of phenological stages of resprouting Terminalia sericea. S Afr J Bot 96:85-90. https://doi. org/10.1016/j.sajb.2014.10.009

Nandwa SM (2001) Soil organic carbon (SOC) management for sustainable productivity of cropping and agro-forestry systems in Eastern and Southern Africa. In: Managing organic matter in tropical soils: scope and limitations. Springer Netherlands, pp 143-158

Niklas KJ (1994) Plant allometry. The scaling of form and process. The University of Chicago Press, Chicago

Niklas KJ (2004) Plant allometry: is there a grand unifying theory? Biol Rev 79:871-889. https://doi.org/10.1017/S1464793104006499

Niklas KJ, Enquist BJ (2002) On the vegetative biomass partitioning of seed plant leaves, stems, and roots. Am Nat 159:482-497. https:// doi.org/10.1086/339459

Noulèkoun F, Lamers JPA, Naab J, Khamzina A (2017) Shoot and root responses of woody species to silvicultural management for afforestation of degraded croplands in the Sudano-Sahelian zone of Benin. For Ecol Manag 385:254-263. https://doi.org/10.1016/j. foreco.2016.11.018

Poorter L, Markesteijn L (2008) Seedling traits determine drought tolerance of tropical tree species. Biotropica 40:321-331. https://doi.org/ 10.1111/j.1744-7429.2007.00380.x

Poorter H, Pothmann P (1992) Growth and carbon economy of a fastgrowing and a slow-growing species as dependent on ontogeny. New Phytol 120:159-166. https://doi.org/10.1111/j.1469-8137. 1992.tb01069.x

Poorter H, Sack L (2012) Pitfalls and possibilities in the analysis of biomass allocation patterns in plants. Front Plant Sci 259:1-10. https://doi.org/10.3389/fpls.2012.00259

Poorter H, Niklas KJ, Reich PB, Oleksyn J, Poot P, Mommer L (2012) Biomass allocation to leaves, stems and roots: meta-analyses of interspecific variation and environmental control. New Phytol 193: 30-50. https://doi.org/10.1111/j.1469-8137.2011.03952.x
Poorter H, Jagodzinski AM, Ruiz-Peinado R, Kuyah S, Luo Y, Oleksyn J, Usoltsev VA, Buckley TN, Reich PB, Sack L (2015) How does biomass distribution change with size and differ among species? An analysis for 1200 plant species from five continents. New Phytol 208:736-749. https://doi.org/10.1111/nph.13571

Reich P (2002) Root-shoot relations: optimality in acclimation and adaptation or the "Emperor's new clothes"? In: Waisel Y, Eshel A, Kafkafi U (eds) Plant roots, the hidden half, 3rd edn. Marcel Dekker, New York, pp 205-220. https://doi.org/10.1201/ 9780203909423.ch12

Reich PB (2014) The world-wide 'fast-slow' plant economics spectrum: a traits manifesto. J Ecol 102:275-301. https://doi.org/10.1111/13652745.12211

Reich PB, Borchert R (1984) Water-stress and tree phenology in a tropical dry forest in the lowlands of Costa Rica. J Ecol 72:61-74. https:// doi.org/10.2307/2260006

Reich PB, Wright IJ, Cavender-Bares J, Craine JM, Oleksyn J, Westoby M, Walters MB (2003) The evolution of plant functional variation: traits, spectra, and strategies. Int J Plant Sci 164:S143-S164. https:// doi.org/10.1086/374368

Reubens B, Achten WMJ, Maes WH, Danjon F, Aerts R, Poesen J, Muys B (2011) More than biofuel? Jatropha curcas root system symmetry and potential for soil erosion control. J Arid Environ 75:201-205. https://doi.org/10.1016/j.jaridenv.2010.09.011

Robinson D (2004) Scaling the depths: below-ground allocation in plants, forests and biomes. Funct Ecol 18:290-295. https://doi.org/10.1111/ j.0269-8463.2004.00849.x

Saïdou A, Kuyper TW, Kossou DK, Tossou R, Richards P (2004) Sustainable soil fertility management in Benin: learning from farmers. NJAS-Wageningen J Life Sci 52:349-369. https://doi.org/ 10.1016/S1573-5214(04)80021-6

StataCorp (2015) Stata 14 base reference manual. Stata Press, College Station

Steege H, Pitman NCA, Killeen TJ, Laurance WF, Peres CA, Guevara JE, Salomão RP et al (2015) Estimating the global conservation status of more than 15,000 Amazonian tree species. Sci Adv 1:e1500936. https://doi.org/10.1126/sciadv.1500936

Sylla MB, Pinghouinde MN, Peter G, Ibourahima K, Nana ABK (2016) "Climate change over West Africa: recent trends and future projections." In: Adaptation to climate change and variability in rural west africa. Springer International Publishing, pp 25-40. https://doi.org/ 10.1007/978-3-319-31499-0 3

Trichet P, Loustau D, Lambrot C, Linder S (2008) Manipulating nutrient and water availability in a maritime pine plantation: effects on growth, production, and biomass allocation at canopy closure. Ann For Sci 814:1-12. https://doi.org/10.1051/forest:2008060 